\title{
Platformization and Internationalization in the LEGO Group
}

\author{
Robert Lorenz Törmer \\ Copenhagen Business School \\ rlt.digi@cbs.dk
}

\author{
Stefan Henningsson \\ Copenhagen Business School \\ sh.digi@cbs.dk
}

\begin{abstract}
Internationalization, to expand a firms territorial footprint, is an important but difficult strategic act for a growing business. Simultaneously, digital technologies are increasingly shaping businesses world-wide and by implication also their internationalization activities as well as strategies. Using experiences from the LEGO Group, the toymanufacturer well-known for its iconic modular bricks concept, we explain how the transformation of the Information Systems (IS) landscape towards a platform architecture is a key enabler for internationalization. Platformization of the IS landscape contributes to mitigate the issues of psychic distance that needs to be overcome when expanding internationally. Based on the insights gained from the LEGO Group, we provide lessons learned for CIO's when enabling an internationalization strategy.
\end{abstract}

\section{Internationalization Drives Business Growth}

In today's global economy, a firm's internationalization strategy is more important than ever. Internationalization, the process of increasing the territory covered by a business' operations across national borders, fuels business growth by reaching new customer groups, connecting to new suppliers and engaging with new innovation ecosystems. The opportunities to expand the business within an international environment have been augmented during the last decades, supported by improved trading laws and regulations. Digital technologies have contributed to the opportunities by enabling coordination of complex supply networks and communication transcending geographical space.

Yet, for the many companies, international expansion remains a hardship. While rising purchasing power in emerging economies creates incentives for established companies to continuously penetrate highly attractive markets [18], the fundamental differences between regions of foreign markets presents barriers for their internationalization ambitions. These barriers are typically referred to as the psychic distance $[16,18]$ that needs to be overcome when transcending geographical borders. Psychic distance describes the economic, cultural, juridical, institutional and geographic difference between the locations where the firm currently operates and the locations that are subject for expansion.

For the LEGO Group, the Denmark-based toy manufacturer well-known for its modular bricksconcepts, internationalization is one of the key strategic pillars to reignite business growth (see Appendix for a description of the research method). From the brink of bankruptcy, the toy-manufacturer has over the last decades experienced strong doubledigit annual growth. While the company is still growing, the last few years have shown a saturation in the current markets. Strategically focused on expanding its international footprint to markets previously not seen as attainable because of the psychic distance, the LEGO Group is rethinking its approach for market entry and reconsiders its capabilities for internationalization.

In this context, the abilities of the company's IS landscape to support the reinvigorated internationalization ambitions has come into consideration. Specifically inspired by large digital platform companies' successes delivering highly diversified offerings that are attractive also for 'the long tail' of customers, the LEGO Group is investing into the platformization of its IS landscape to better support internationalization ambitions.

Focusing on these efforts and their effects, we present the role of platformization in the LEGO Group's past, present and future internationalization journey. Based on the premise that a company's internal digital platform enables responsiveness to local market demands and legal requirements [27], the case data reveals how the pre-existing IS landscape has constrained the company's internationalization activities in the past. Furthermore, the evidence elaborates how the company's current platformization 
efforts are enabling international expansion in the future by mitigating some of the barriers associated with psychic distance.

\section{Internationalization and Psychic Distance}

For more than five decades, the field of international business (IB) has produced research contributions to describe, explain, and predict how companies internationalize [20] and has mainly been dominated by three theoretical perspectives: internationalization theory, the Uppsala model of internationalization, and the eclectic paradigm. Independently from research subject or theoretical orientation, Rugman et al. [20] emphasize that the center of IB theory and management practice continues to evolve around the role of 'distance' for transferability, recombination, and exploitation of organizational capabilities.

The core argument of internationalization theory is that (intermediate and output) market imperfections across national borders create incentives for firms to internalize intermediate markets and establish facilities abroad instead of exporting to foreign markets [4]. In this context, the concept of firm-specific advantages has been developed to explain why certain enterprises are particularly well-suited to benefit from internationalization activities. This point has also been picked up by the Uppsala model, which initially sought to explain the incipient internationalization process of firms from small, domestic markets. Johanson and Vahlne $[15,16]$ paint the internationalization process as cumulative and path-dependent on a firm's previous expansion pattern, experience as well as knowledge base. Therefore, internationally inexperienced firms typically start by entering foreign markets through exports and subsequently progress by establishing sales subsidiaries and potentially production facilities through direct investment [16].

At its core, the Uppsala process model suggests that distinct forms of distance - i.e. cultural, economic, institutional, geographic distance (c.f. Figure 1) produce cost of employing firm-specific advantages abroad and thereby potentially outweigh the benefits of doing so. Combining these distinct forms in the concept of psychic distance, Johanson and Vahlne [7, p.13] accordingly predict that companies will initially expand into foreign markets where these forms of distance are particularly low and subsequently "enter new markets with successively greater psychic distance". In a similar vein, Hymer [14] refers to liability of foreignness that needs to be offset by firmspecific advantages in relation to a certain country.
In subsequent refinements of the original Uppsala model, Johanson and Vahlne [17] first proclaim that competitive success in a foreign market primarily depends on powerful relationships with actors in a host country's business network. The absence of such relationships constitutes a liability of outsidership that prevents companies from overcoming psychic distance and realizing country-specific advantages [17]. Rugman et al. [20], on the other hand, call for more research focus on regional strategy and advance the notion of interregional foreignness, which describes resource recombination barriers caused by psychic distance between cross-national market regions. A later adaptation by Vahlne and Johanson [29] puts specific emphasis on the evolution and learning mechanisms in multi-national enterprises (MNEs). Resulting from opportunity-seeking resource commitments, knowledge-development processes enrich and enhance specific capabilities - embodying firm-specific advantages - that are crucial for overcoming psychic distance associated with foreign markets.

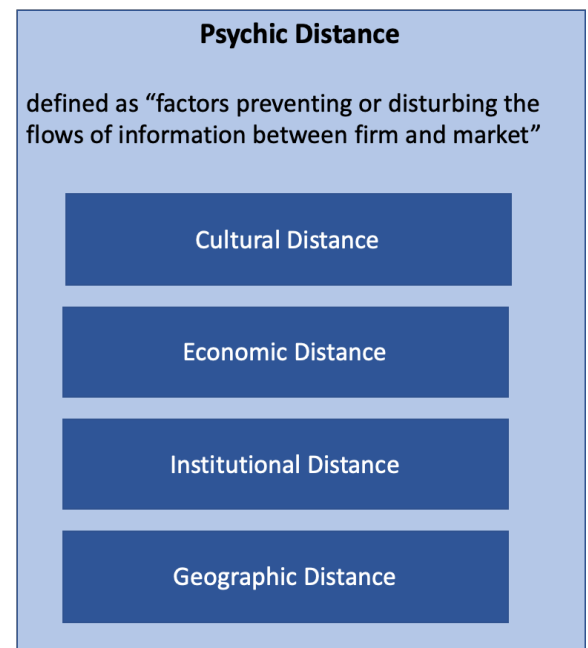

\section{Figure 1. Dimensions of Psychic Distance according to Johanson and Vahlne [15]}

The increasing significance of digital technologies for businesses across industries "has profoundly changed the character and the geographic distribution of IB activity" [1, p.500]. At the same time, IB research has only addressed this change to a limited extent [26]. Specifically, on the level of individual organizations, IB studies have primarily focused on the impact of e-commerce and the influence of major Internet companies [26]. In the context of international expansion of traditional MNEs, "theoretical exploration of potential uses of these new technologies are yet to emerge" [5, p.77].

Among the few existing contributions, Santangelo [21] argues that ICTs allow companies to build 
capabilities, which enable the expansion of corporate activity across national boundaries. "Therefore ICT can be viewed as a platform for entry into new products as well as an enabler of fusion of technology" [12, p.701]. Scrutinizing the Uppsala model in the context of digital companies, Coviello et al. [7] add macro-level influences, such as digitalization, as a central dimension to the process model. They argue that "digitization has the potential to impact [...] the firms' ability to manage the liabilities of foreignness and outsidership [and] enables greater transferability of firm-specific assets" [3, p.1153]. In a similar vein, Eduardsen [10] proclaims that the Internet along with the rise of e-commerce has reduced the relevance of distance. Therefore, it is nowadays "commonly assumed that the Internet is an enabling technology, making internationalization a viable growth strategy for even the smallest firm" [4, p.160].

\section{IS Landscape Platformization}

The academic literature on technological platform management mainly consists of two separate research strands. On the one hand, the economic theoretical perspective has conceptualized platforms as two-sided markets and has produced insights on platform competition. In this vein, platforms act as conduits of market transactions that drive transaction efficiency and reduce search costs in the exchange of goods and services [11]. Specifically Tiwana [22, p.50] reveals that "by tapping into both mass markets and long-tails of those markets through extensive customization by end-users, [multi-sided platforms] can capture a larger extent of the market than even mass-produced products".

The technological engineering perspective, on the other hand, studies platforms as technological architectures that drive platform innovation [11]. For this purpose, they are classified into stable core and variable peripheral components that interact via standardized interfaces [2]. This conceptualization explains how modular architectures spur product variety by providing a technological architecture to innovate upon in production and design $[9,11]$. This architecture may be used only within the boundaries of a single company or across several organizations. In the context of IS, the platform concept is increasingly utilized to conceptualize how individual companies can holistically structure their internal landscapes of IS to effectively enable business in the digital age $[22,23$, 27]. Within the context of this study, an IS landscape refers to a company's holistic collection of all technology infrastructure, business logic, and data that serves internal employees across business functions and external business partners. Specifically "the proliferation of digital tools or digital components allows firms to build a platform not just of products but of digital capabilities used throughout the organization to support its different functions" [28, p.1400].

Capturing the increasing orientation towards platform thinking in practice, terms, such as "platform coring" $[12,25]$ and "platformization", have emerged in the IS literature to describe the commercial transformation from products to (multi-sided) platforms $[3,6]$ or the establishment of large-scale platform architectures to spur innovation within as well as across organizations $[5,28]$. According to Benlian et al. [3, p.724], platformization "builds on decoupling and characterizes the process in which an entity (a provider organization) creates access and interaction opportunities centered around a core bundle of services (the platform) within an ecosystem of consumers, complementors, and other stakeholders". While their conceptualization subscribes primarily to the multisided platform notion, this study follows the technological engineering perspective on platforms. Consequently, platformization is conceptualized as the socio-technical process of transforming a large-scale IS towards a platform architecture. This architecture is characterized by a core of stable functionality, a periphery of increasingly variable components, and component interactions via standardized, de-coupled interfaces [27].

\section{Case Evidence: The LEGO Group's Journey in China}

As one of the first brick-and-mortar companies in the world, the LEGO Group made digitalization a fundamental pillar of the overall business strategy already in 2012. To meet present and upcoming challenges, the long-term vision for the toy manufacturer from Denmark is to create a highly adaptive organization, which collaborates closely with external partners to harness an ecosystem of platforms to co-create innovation. Since the implementation of this agenda placed heavy demands for novel functionality on the company's enterprise systems, the need for a new platform architecture became apparent to create the foundation for the company's future digitalization journey and commercial agenda.

\subsection{The LEGO Group's Past IS Landscape}

The LEGO Group's physical value proposition relies on a mature operating model that is implemented in a core of largely non-redundant enterprise systems, which enable efficient operational transactions through globally standardized and integrated business processes 
(c.f. Figure 2). In the past decade, the company's IS landscape has been shaped by the strategic direction to leverage externally-created off-the-shelf enterprise systems wherever possible. As a result, the centerpiece of the landscape largely relies on non-redundant SAP systems that have been configured as well as customized to specific company needs.

The establishment of technical and business process integration among distinct landscape components relies on several mechanisms. While integrations among core SAP systems are established through proprietary pointto-point (P2P) connections, the reuse of data and functionality by other systems relies to a large extent on a custom-developed, batch-based integration system. In addition, few parts of the IS landscape have started to rely on decoupled API-based integration. Particularly in the periphery of the landscape, the socalled consumer engagement platform emerged that allows for the rapid development of content-based digital experiences and a two-way interaction with systems limits the speed of implementing changes or system upgrades due to ripple effects and the subsequent need to modify other landscape components as well. In addition to tight coupling among landscape components, the customization and extension of existing off-the-shelf enterprise systems furthermore hinders the implementation of changes as well as upgrades. Furthermore, the LEGO Group's IS landscape is currently challenged with increasing needs to integrate purpose-specific and potentially cloudbased applications and services quickly.

\subsection{Common Technology-Related Challenges for Foreign Companies Entering China}

The Chinese market exhibits several specific characteristics, which commonly pose very challenging demands on foreign companies optimized for western market conditions. For once, China generally imposes peculiar legal requirements that are cumbersome to

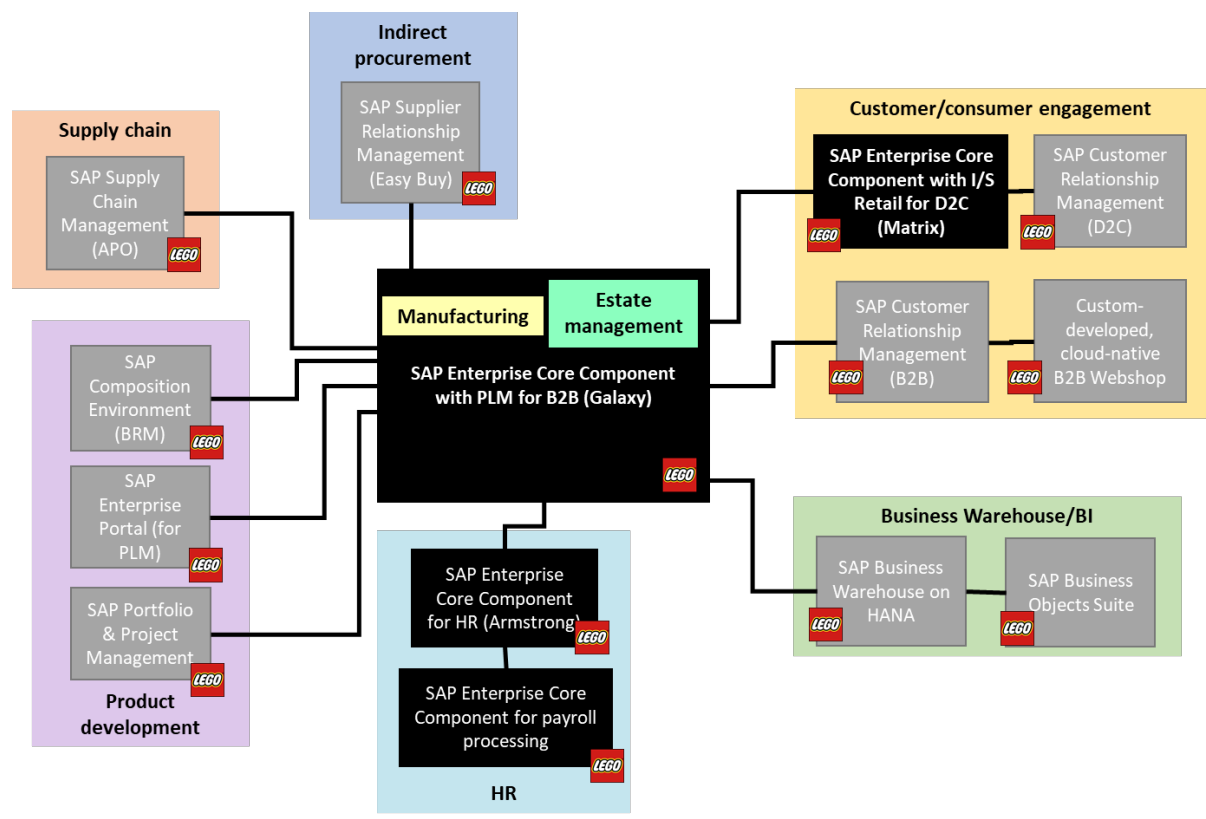

Figure 2. The LEGO Group's core enterprise systems excluding surrounding components

customers as well as consumers. Over the years, the platform has produced distinct digital experiences, including the LEGO Group's websites for children and adults, distinct games, various TV apps and the social network LEGO Life.

While this IS landscape has been the foundation for an extremely successful operating model that enabled the company's double-digit growth for more than a decade after 2004, technical complexity is increasingly limiting its upgradability and evolvability. For once, the abundance of tight coupling among enterprise fulfill from an information technology (IT) perspective. For instance, special tax receipts need to be printed on the tax bureau's dedicated printing machines, which are specially designed and integrated into the tax system.

Secondly, the specific legal requirement that foreigners are not allowed to publish content on the internet in China specifically complicates marketing operations. Consequently, a Chinese party in the middle is required to publish marketing material on behalf of foreign companies. Thirdly, data protection 
laws require that personal identifiable information remains stored on servers within the country. This regulation mainly complicates the use of CRM systems or consumer engagement solutions.

Eventually, the "Great Firewall of China" makes data import and export eminently challenging, since systems have to leverage VPN (Virtual Private Network) or MPLS (Multiprotocol Label Switching) connections to integrate with systems hosted outside of China. These connections are very strictly governed by authorities and require special approvals that can only be obtained through long-lasting application processes. Moreover, the connections are subject to legal requirements that each introduce additional complexity from a technical perspective. For instance, VPN connections should not allow users within China to access the internet in the outside world.

\subsection{The LEGO Group's Market Entry and Penetration in China}

The LEGO Group's relations with the Chinese market date back to the 1980s and have for a long time relied on a single retail customer to sell LEGO products in China out of production in Europe. It was not until 2012 that the LEGO Group established a sales company in China to target additional wholesale customers under the holistic Asian market group. Due to the market's increasing commercial importance and in aspiration of market proximity, the decision to build a factory in Jiaxing was announced in 2013. Almost simultaneously, a Hub office in Shanghai as well as a dedicated market group were established around 2014 that underlined the market's strategic importance for the organization and implied dedicated operations in the country. The Jiaxing factory eventually ramped up production in 2015. Over the years, the LEGO Group has continuously realized very strong growth in the Chinese market. Through the 2014-16 period, Gross Revenue has tripled and Market Contribution has more than quadrupled. The LEGO Group is reaching approximately 2 million children in China, with an ambition to reach more than 9 million in 2025 . Looking towards, 2020 the company aims to grow Consumer Sales 30 percent annually and improve financial profitability through seeking continuous improvement and economies of scale.

However, the company's increasing operations in China have been accompanied by a complex technology roll-out, which started out by reusing as much of the existing enterprise systems as possible without introducing new redundancies (incl. the single instance enterprise resource planning system). This roll-out has posed specific demands on the operating model and IS landscape.
China's reporting legislation requirements have been addressed by implementing deviations from the LEGO Group's globally standardized business processes. The LEGO Group is very committed to legal compliance and these requirements imply exceptions to global standards that subsequently undermine operational efficiency for business and IT. "The tax regulation and the tax thinking was something we had to understand and adapt our global template to. [...] [SAP] probably provided some [of that functionality] but a lot of the models are LEGO models in our global template of optimizing manufacturing efficiency in Western Europe" (Principal Enterprise Architect (EA), LEGO Group).

Due to content publishing regulations, owndeveloped LEGO apps had not been provided to the Chinese market for several years. Particularly for the publication of digital experiences, the LEGO Group has partnered with Chinese internet company Tencent to provide safe and imaginative digital LEGO content that supports children's needs of learning, development and entertainment. "There is a technical gap to the consumer in that the consumer does not have access to our traditional way of engaging with consumers being Facebook, Google, Twitter - these traditional platforms. It is very difficult to put up a web-shop in China because of the legal restraints. [...] The consumers are on different platforms [... and] consumer engagement is a pre-requisite for success in any space" (Senior EA, LEGO Group).

The requirement to store personal identifiable information on local servers mainly impacted the operation of CRM and digital consumer engagement solutions (e.g. LEGO Life) within the country. Based on the LEGO Group's one-instance philosophy, these systems would conventionally host functionality and data in centralized data centers in Europe that are merely accessed via a client user interface. Establishing a second instance for these systems within China would challenge global business process standardization, complicate data integrity as well as analysis, and subsequently also reduce IT efficiency.

Also, the connectivity of local solutions through the Great Firewall of China is currently realized through MPLS connections allowing for access to enterprise systems, but preventing access to the public internet. Again, since the LEGO Group is particularly committed to legal compliance, the implementation of these requirements is of highest strategic priority. "So far, we have had a network connection directly through the Great Firewall that we have been able to utilize for our own corporate data. [... We are not] allowed to use this gateway or tunnel through to the Chinese consumer, because there are requirements to network providers in China" (Senior EA, LEGO Group). 


\subsection{Platformization of the IS landscape}

In order to address previous restrictions on digital innovation posed by a highly efficient, but tightly coupled IS landscape, the LEGO Group established a centralized Enterprise Architecture (EA) capability in early 2017. Subsequently, the establishment and continuous construction of this capability initiated the transition towards a centrally guided, flexible platform architecture that should "allow the LEGO Group to identify and realize real options by providing longterm sustainable, scalable and adaptable IT platforms that ensure that the business agenda is not limited by EA choices" (Source: the LEGO Group). This transition has been further accelerated by the development of a new Technology Strategy and Roadmap for the entire organization that puts the goal of an agile platform architecture at the core of dedicated significant investments into technology for the future. Thereby, the strategy seeks to enable the company's commercial agenda (including geographical expansion), address critical technology pain points, drive IT-enabled business flexibility, and afford future digital innovation. "If implemented correctly, [...] that would enable us to choose more local components whereas the core components can remain unchanged. [...] However, that requires a conscious integration effort in defining what is global, what is local, what is core, and what is periphery - also on the process layer" (Senior EA, LEGO Group).

While the LEGO Group has adapted to the Chinese market through ad-hoc solutions to the operating model and IS landscape so far, China is only the first of multiple countries that will imply such adaptations. In order to fulfill the strategic ambition to expand global presence and reach 200 million children by 2025 , the LEGO Group will continuously focus on new emerging markets that may bear similar challenges. This will not only depend on the successful transition towards a more flexible platform architecture, but will also require an overarching architecture game plan of how specific (legal) requirements of new market regions can be addressed. "China is a very different market to what a market entry in traditional LEGO terms had meant previously. We had been used to entering markets in the western hemisphere - mainly Europe and North America. And they have been not entirely alike, but culturally and legally widely aligned. However, as the LEGO Group is expanding its geographical reach, we are experiencing more and more diverse cultures, frameworks, and also now the impact of very diverse technology platforms in countries we are entering" (Senior EA, LEGO Group).

\section{How Platformization enables Internationalization}

The case evidence reveals how the LEGO Group's past market entry and penetration in China have been enabled as well as constrained by the company's existing global IS landscape. Even though the company's journey in China has been highly successful from a business perspective, the reactive adaptation of global solutions, which embody standardized business processes and have been optimized for the European as well as North-American markets, has created specific barriers to the efficiency and effectiveness of establishing local business operations.

For once, compliance to local legislation in terms of reporting as well as data protection has been established through cumbersome customizations and workarounds within the global ERP template that had previously been optimized for homogeneous legal requirements in Western Europe and North-America. This procedure complicated market entry and limited future system flexibility. The LEGO Group's deliberate investment into IS landscape platformization, on the other hand, is enabling future adaptation to local legislation through (1) more seamless adoption of vendor-provided software upgrades, (2) smoother connectivity to third-party solutions and (3) architecturally sound implementations of local exceptions to the global template. The ability to adapt to local legislation more efficiently and effectively lowers the impeding effect of institutional distance on the internationalization process. This reasoning supports mechanism 1:

M1: A platformized IS landscape enables a company to overcome the psychic distance to a specific market region by increasing responsiveness to peculiar local legislation.

Operating in the consumer-goods industry, the LEGO Group is following a customer engagement strategy. By offering digital experiences to consumers as well as shoppers, generated data is leveraged to develop new value propositions and improve existing ones. Consequently, two-way interactions with consumers and shoppers are a necessary pre-condition to derive insights into behavior as well as preferences and to ensure that value propositions remain relevant. Specifically in the context of cross-national cultural differences, data-driven insights play a vital role for establishing local responsiveness to customer needs. Applying this strategy in foreign market regions, a company can overcome the cultural and economic dimensions of psychic distance more effectively and efficiently by leveraging data-driven insights to learn 
about purchasing behavior and country-specific customer preferences.

On the one hand, the technical ability for digital two-way interactions has been identified as a generic affordance offered by platforms in the IS literature. Additionally, the case evidence reveals that the ability to develop digital experiences for customer engagement and tailor them to country-specific as local payroll solutions. Since most of these platforms are loosely affiliated actors that perform business transactions through standardized, public application programming interfaces (APIs), the IS landscape's affordance to support such connectivity is a vital capability to support the internationalization process. By facilitating connectivity to digital partner networks, a platformized IS landscape therefore allows

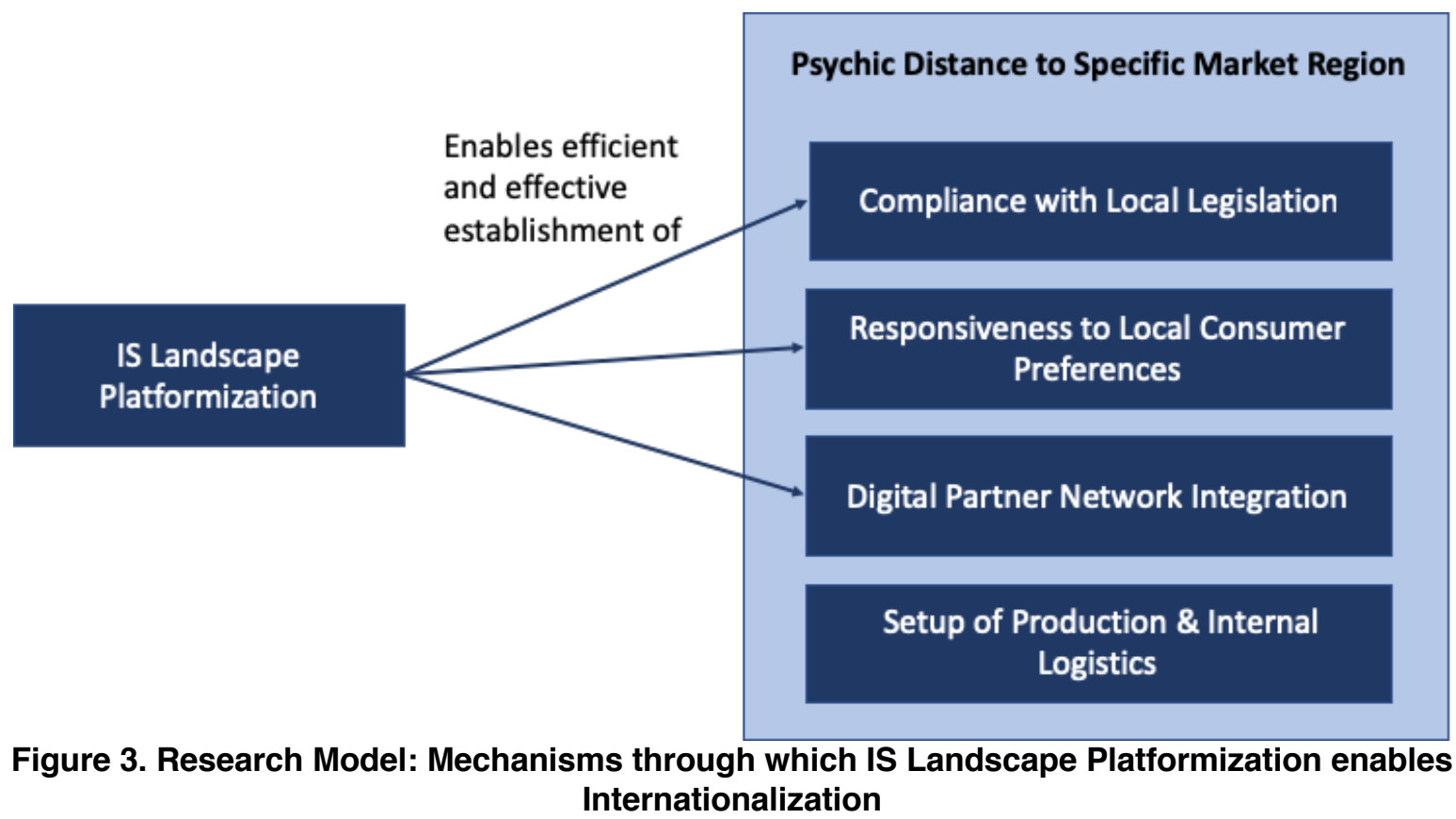

legislation relies on the platformization and subsequent flexibility of a company's IS landscape. Consequently, the case evidence supports mechanism 2:

\section{M2: A platformized IS landscape enables a} company to overcome the psychic distance to a specific market region by increasing responsiveness to local customer preferences through customer engagement and data-driven insights.

In addition to internally-developed digital experiences, this ability may equally hinge on digital partnerships with local technology platforms to publish content in compliance with local data legislation. The LEGO Group, for instance, has entered a partnership with a local platform company to outsource the publishing capability for China. Moreover, the continuous internationalization journey reveals a need to connect to a large quantity of heterogeneous technology platforms in distinct countries - not only for customer engagement, but also for business capabilities from the traditional enterprise world, such companies to overcome institutional and geographic distance more efficiently as well as effectively. Subsequently, the "liability of outsidership", which has been advanced by network perspectives in internationalization research, can be mitigated. Accordingly, mechanism 3 follows from this reasoning:

M3: A platformized IS landscape enables a company to overcome the psychic distance to a specific market region by enabling connectivity to digital partner networks and platforms.

While mechanisms 1,2 and 3 reveal how platformization does enable a company's internationalization capability, the case evidence does not point towards any facilitating mechanism regarding the setup of production and internal logistics specifically. The LEGO Group simply applied its template of highly standardized and integrated business processes for production in China. The only local adaptations required for the specific market were related to legal requirements for reporting and taxation 
during the movement of money or goods. Even though these requirements did impact the efficiency and effectiveness of setting up business operations in China, they are caused by local legislation, relate to cultural as well as institutional distance, and are therefore explained by mechanism 1 .

Taken together, the three mechanisms elaborated in this section form the foundational pillars of our theoretical model depicted in Figure 3. The model reveals the overall finding that companies can deliberately invest into IS landscape platformization to remove barriers to internationalization and enable future market entry as well as penetration in potentially less attractive market regions with higher compounded distance. By building the capability to overcome distinct forms of distance associated with a specific market region more effectively and efficiently, the commercial attractiveness of any foreign market will subsequently be increased for the company. This observation relates to Tiwana's [25, p.50] argument that multi-sided platforms hold dramatically superior market potential in comparison to products "by tapping into both mass markets and long-tails of those markets through extensive customization". Similarly, the platformization of an internal IS landscape enables the delivery of highly diversified offerings that are attractive also for 'the long tail' of customers.

\section{Lessons Learned}

With basis in the LEGO Group's work to platformize its IS landscape to enable its reinvigorated internationalization ambitions, we have distilled three lessons learned to guide IT managers when embarking on a similar journey.

\subsection{Platformization is not a silver bullet}

The hardship of internationalization has been a known issue for a long time. Gradually, some of the barriers for internationalization have been lowered, with the reduction of legislative barriers and the buildup of sophisticated logistics networks. These changes affect everyone equally and give no firm a particular edge towards competitors. Platformization addresses the internationalization problem from a different angle: increasing the firm's ability to deal with it. In contrast to lowered barriers, increasing the ability to deal with the barriers gives a competitive edge towards customers that can be hard to imitate.

It is, however, important to recognize that platformization is not a silver bullet that immediately makes internationalization unproblematic. What we saw in the LEGO Group case was that the initiative has the potential to contribute towards easing some part of the economic, juridical and institutional issues. There are clearly large parts of these issues that platformization does not solve. In addition, we could not find any evidence that platformization contributes towards solving the geographical issues with internationalization. Therefore, platformization in itself does not solve the internationalization problem, but it helps towards a resolution.

\subsection{Platformization is a journey, not a project}

The IS landscapes that large incumbent firms have today have been built over decades with additions and incremental changes to what already existed. Present systems typically count in hundreds or even thousands. Anyone who has been involved in a major system replacement knows the hard work that goes into the retirement of components, introduction of new ones, and the management of interdependencies to other system components.

It follows that complete IS landscapes as not rearchitected as one large effort, where the IT management pushes a completely new setup. In the LEGO Group, platformization is a gradual journey that in its essence took its starting point with the establishment of an EA department to oversee that each change to the IS landscape would move it towards the ideal platform architecture. It was also recognized that this journey may never be completed. Other priorities would always interact with the architectural priorities to form the actual IS landscape. Priorities of cost, time, specific functionality or software vendor preferences will make their mark. The importance, however, is that the journey continues by the pace that is possible to mount and that - as shown by the LEGO Group's case - also gradual increases in platformization can have substantial impact on the enablement of an internationalization strategy.

\subsection{Start where it hurts the most}

Any journey has a start. This start should be adapted to where the problems are. Because every company is unique, working in a different industrial context, the internationalization issues will be differently prevalent in these contexts. For example, a financial company is likely to find the major challenges of internationalization to be in the juridical and institutional differences between existing and new markets. Geographical distance may be a minor issue for digital financial products. In contrast, a firm with a strong design-focus addressing a private consumer market would likely find the most prevalent barrier to internationalization in differences between consumer 
likings. In addition, different markets contribute their specific characteristics. In one country, the juridical distance can be particularly salient, but in another one the institutional distance is the major hurdle.

Naturally, when thinking of the platformization journey, it is important to tailor the endeavour to the specific internationalization strategy of the firm. A basis in an understanding of the industry conditions of internationalization and a view of the key countries targeted as the first step of the expansion, is important to channel initial platformization efforts to where they are critically needed. In the LEGO Group, considering the industry context and the ambition to grow presence in China, this put a focus on the key issue of how to engage with a partner network and the ability to customize product to the Chinese-speaking consumer. This insight guided the initial investments in platformization as well as marked that in these specific areas the degree of platformization should remain as a key priority when continuously crafting the IS landscape in the future.

\section{Conclusions}

As business capabilities are increasingly embodied in enterprise systems and digital experiences, the IS landscape becomes a strategic resource underpinning a company's ability to expand internationally. In this contribution, we have identified three mechanisms through which the platformization of a company's IS landscape enables the efficient and effective establishment of (1) compliance with local legislation, (2) responsiveness to local consumer preferences, and (3) digital partner network integration. In combination, these mechanisms do not guarantee, but facilitate triumph over psychic distance to a specific market region by addressing distinct subordinate forms of distance on their own. Consequently, IS landscape platformization may enable companies to invest into market entries that would not have been profitable otherwise.

In addition to the high-level recommendation that companies targeting far-reaching international expansion should invest into the platformization of their IS landscapes, this paper additionally provides several lessons learned for CIO's embarking on the journey. These lessons particularly emphasize the continuous - and probably endless - nature of the platformization journey, the orchestrating role of the EA capability during the process, and the need to align platformization efforts with strategic priorities in the company.

\section{References}

[1] Alcácer, J., J. Cantwell, and L. Piscitello, "Internationalization in the information age: A new era for places, firms, and international business networks?", 2016. [2] Baldwin, C.Y., and C.J. Woodard, "The architecture of platforms: A unified view", Platforms, markets and innovation, 2009, pp. 19-44.

[3] Benlian, A., W.J. Kettinger, A. Sunyaev, T.J. Winkler, and G. EDITORS, "The transformative value of cloud computing: a decoupling, platformization, and recombination theoretical framework", Journal of management information systems 35(3), 2018, pp. 719-739.

[4] Buckley, P.J., "Inside the multinationals: The economics of internal markets. Alan M. Rugman, inside th multinationals: The economics of internal markets, Croom Helm, London, 1981, pp. 179.£ 11.95”, Managerial and Decision Economics 6(1), 1985, pp. 64-65.

[5] Bygstad, B., and O. Hanseth, "Transforming Digital Infrastructures Through Platformization", 2018.

[6] Constantinides, P., O. Henfridsson, and G.G. Parker, "Introduction-Platforms and infrastructures in the digital age", 2018.

[7] Coviello, N., L. Kano, and P.W. Liesch, "Adapting the Uppsala model to a modern world: Macro-context and microfoundations", Journal of International Business Studies 48(9), 2017.

[8] Dubé, L., and G. Paré, "Rigor in information systems positivist case research: current practices, trends, and recommendations", MIS quarterly, 2003, pp. 597-636. [9] Eaton, B., S. Elaluf-Calderwood, C. Sorensen, and Y. Yoo, "Distributed tuning of boundary resources: the case of Apple's iOS service system", Mis Quarterly 39(1), 2015, pp. 217-243.

[10] Eduardsen, J., "Internationalisation Through Digitalisation: the Impact of E-Commerce Usage on Internationalisation in Small-and Medium-Sized Firms", In International Business in the Information and Digital Age. Emerald Publishing Limited, 2018, 159-186.

[11] Gawer, A., "Bridging differing perspectives on technological platforms: Toward an integrative framework", Research Policy 43(7), 2014, pp. 1239-1249.

[12] Gawer, A., and M.A. Cusumano, "How companies become platform leaders", MIT Sloan management review 49(2), 2008, pp. 28.

[13] Hazlehurst, C., and K.D. Brouthers, "IB and Strategy Research on 'New' Information and Communication Technologies: Guidance for Future Research", In International Business in the Information and Digital Age. Emerald Publishing Limited, 2018, 65-89.

[14] Hymer, S.H., International operations of national firms, MIT press, 1976.

[15] Johanson, J., and J.-E. Vahlne, "The internationalization process of the firm - a model of knowledge development and increasing foreign market commitments", Journal of international business studies 8(1), 1977, pp. 23-32.

[16] Johanson, J., and J.-E. Vahlne, "The mechanism of internationalisation”, International marketing review 7(4), 1990.

[17] Johanson, J., and J.-E. Vahlne, “The Uppsala internationalization process model revisited: From liability of 
foreignness to liability of outsidership", Journal of international business studies 40(9), 2009, pp. 1411-1431. [18] Marquis, C., and M. Raynard, "Institutional strategies in emerging markets", The Academy of Management Annals 9(1), 2015, pp. 291-335.

[19] Naur, P., Program development studies based on diaries, na, 1983.

[20] Rugman, A.M., A. Verbeke, and Q.T.K. Nguyen, "Fifty years of international business theory and beyond",

Management International Review 51(6), 2011, pp. 755-786.

[21] Santangelo, G.D., "The impact of the information and communications technology revolution on the

internationalisation of corporate technology", International

Business Review 10(6), 2001, pp. 701-726.

[22] El Sawy, O.A., P. Kræmmergaard, H. Amsinck, and

A.L. Vinther, "How LEGO Built the Foundations and

Enterprise Capabilities for Digital Leadership.", MIS

Quarterly Executive 15(2), 2016.

[23] Sebastian, I.M., J.W. Ross, C. Beath, M. Mocker, K.G.

Moloney, and N.O. Fonstad, "How Big Old Companies

Navigate Digital Transformation.”, MIS Quarterly Executive, 2017.

[24] Tiwana, A., Platform ecosystems: aligning architecture, governance, and strategy, Newnes, 2013.

[25] Toppenberg, G., S. Henningsson, and B. Eaton,

"Reinventing the Platform Core Through Acquisition: A

Case Study", 2016 49th Hawaii International Conference on System Sciences (HICSS), IEEE (2016), 4634-4643.

[26] Van Tulder, R., A. Verbeke, and L. Piscitello,

"Introduction: International Business in the Information and

Digital Age-An Overview of Themes and Challenges", In

International Business in the Information and Digital Age.

Emerald Publishing Limited, 2018, 1-13.

[27] Törmer, R.L., "Internal Digital Platforms and

Generative Mechanisms of Digital Innovation", Proceedings

of the 39th International Conference on Information Systems,

(2018).

[28] Törmer, R.L., and S. Henningsson, "From Drift to Central Guidance: A Path Constitution Perspective on the

Platformization of an Information Infrastructure",

Proceedings of the 25th European Conference on

Information Systems, (2018).

[29] Vahlne, J.-E., and J. Johanson, "From

internationalization to evolution: The Uppsala model at 40

years", Journal of International Business Studies 48(9),

2017, pp. 1087-1102.

[30] Yin, R.K., Case study research: Design and methods, SAGE Publications, 2013.

[31] Yoo, Y., R.J. Boland Jr, K. Lyytinen, and A. Majchrzak, "Organizing for innovation in the digitized world",

Organization Science 23(5), 2012, pp. 1398-1408.

\section{Appendix: Method}

The research presented in this paper adopts a case study approach [30] to explore how the platformization of a company's IS landscape enables its internationalization capability. The goal has been the construction of an explanatory theory to elaborate how and why phenomena occurred. Since the inquiry investigates a rare phenomenon in a fine-grained level of detail, a single-case design is suitable to produce significant research results [8].

The study was designed to initially cover a broad scope and was based on the collection of empirical data to allow for a partially inductive understanding of the platformization initiative in the LEGO Group. Data was collected from three sources of evidence: observations, documents and interviews. Direct participant observation data [30] was collected by one of the authors that for 28 months acted as an integrated member of the LEGO Group's EA management team on site at the group's headquarters in Billund, Denmark. Observation data and information about relevant supporting material (documents), were captured in a structured diary [19]. The diary entries were collected in a case database and each grouped by direct observations, reflections on observations, plans for future research, and supporting diagrams, drawings, or mind-maps. Thirty semi-structured interviews with key informants are used as a secondary source of evidence [30]. The interviews were conducted on the company's premises and supported by an interview guide containing open-ended questions. The informants mainly include Enterprise or Solution Architects as well as senior stakeholders, such as Vice Presidents of Corporate IT. All interviews were recorded, transcribed and added to the case database [30]. For the purpose of further triangulation, internal documents from the company, such as reports, presentations, emails, and architecture documentation, are used as a third source of evidence [31].

Based on an initial analysis of the case data, we approached the initiative as a theoretical issue extending and challenging our emergent findings. Stimulated by the emerging event sequences around the platformization of the LEGO Group's IS landscape, we turned to the IB literature to analyze the phenomenon in the context of the field's existing theory. Finally, we used our empirical observations to create an initial case narrative that is supported with interview quotes to increase its vividness and transparency. Eventually, members of the initiative assessed the representativeness of the findings in our narrative [31]. Largely, the perception concurred with our emergent explanation, revealing the need for only marginal adjustments to the narrative. 